\title{
Natural infection of synathropic rodent species Mus musculus and Rattus norvegicus by Leishmania infantum in Sesimbra and Sintra - Portugal
}

\author{
Marcos Helhazar ${ }^{1 \dagger}$, José Leitão ${ }^{2 \dagger}$, Ana Duarte ${ }^{1 \dagger}$, Luís Tavares ${ }^{1}$ and Isabel Pereira da Fonseca ${ }^{1 *}$
}

\begin{abstract}
Background: Canine leishmaniosis caused by Leishmania infantum is a parasitic zoonotic disease transmitted by phlebotomine sandflies (Diptera: Psychodidae). Genus Phlebotomus is the biological vector in the Old World and Lutzomyia in the New World. The dog is the domestic reservoir host but other animals like the fox (Vulpes vulpes) and rodents are known to maintain the infection in both sylvatic and domestic cycles.

Methods: To identify the role of synanthropic rodents Mus musculus and Rattus norvegicus as reservoir hosts for Leishmania infantum natural infection, 30 rodents were captured under a trap rodent control program in two private dog shelters from Sintra and Sesimbra, located in the Lisbon Metropolitan Area, known to be endemic for canine leishmaniosis in Portugal. Tissue samples were screened for the presence of Leishmania amastigotes by qPCR and parasitological analysis.

Results: A total of $33.3 \%$ (9/27) of Mus musculus rodents revealed the presence of Leishmania spp. DNA while $29.6 \%(8 / 27)$ were positive in the parasitological analysis. Concerning Rattus norvegicus $(n=3)$, one animal revealed infection only by parasitological analysis.

Conclusions: Our results identified for the first time in Portugal the presence of Leishmania infection in both rodent species. As susceptible hosts, infected Mus musculus and Rattus norvegicus may increase the risk for dog and human infection in households and surrounding areas, enhancing the need for efficient rodent control measures in shelters and risk zones to prevent transmission of the infection.
\end{abstract}

Keywords: Leishmaniosis, Leishmania infantum, Rodents, Mus musculus, Rattus norvegicus, Reservoir

\section{Background}

In Europe, visceral zoonotic leishmaniosis is a protozoan disease caused by Leishmania infantum. The parasite is transmitted by female infected sandflies from the genus Phlebotomus during feeding. The domestic dog is the main reservoir host for Leishmania infantum but other reservoirs are known, such as wild carnivores and rodents [1-3]. In Portugal, canine leishmaniosis is an endemic disease with an infection rate of $6.31 \%$ obtained during a serological survey performed in 3.974 dogs from veterinary clinics in Mainland Portugal [4]. Recently, the domestic cat has also been suggested as a

\footnotetext{
* Correspondence: ifonseca@fmv.utl.pt

'Equal contributors

'CIISA, Fac Med Vet, Av, Universidade Técnica, 1300-477, Lisboa, Portugal

Full list of author information is available at the end of the article
}

reservoir host and in Northern Portugal, a 2.8\% seroprevalence was found in 316 domestic cats [5].

Man can be infected by Leishmania infantum, especially in cases of immunodeficiency caused by diseases such as AIDS or other conditions [6]. In Portugal, between 2000 and 2009, 173 cases of human visceral leishmaniosis were diagnosed. The emergence of 15 to 20 new cases is estimated yearly [7].

The disease is transmitted by Phlebotomus perniciosus and Phlebotomus ariasi, both sandfly vectors reported in Portugal [7]. Alternative ways of transmission such as blood transfusion, vertical and venereal transmissions have also been inferred [8].

The identification of natural hosts of Leishmania is fundamental to better understand the epidemiology of the disease. Due to close proximity between rodents, dogs and

\section{C) BïoMed Central}


humans, the importance of rodents as reservoir hosts for different Leishmania species have already been described worldwide [3]. In Brazil, several authors reported infected rodents in natural conditions with Leishmania spp. [9-11] and $L$. donovani complex, L. mexicana complex and L. braziliensis complex [12]. The same occurred in Venezuela with identification of $L$. donovani complex [13,14] and Leishmania sp. [7]. In Mexico, Leishmania spp. were reported [15]. In Italy, L. infantum, was identified [16], as well as in Cyprus [17] and Greece [18]. In Iran, $L$. major, L. turanica, $L$. donovani, $L$. infantum, $L$. major and L. gerbilli were also detected [19-23].

In Portugal, to our knowledge no data is available concerning natural Leishmania infection in any rodent species. The aim of this work was to investigate the role of Mus musculus and Rattus norvegicus rodents as natural reservoirs for Leishmania spp. in Sintra and Sesimbra, both canine leishmaniosis endemic areas in Central Portugal.

\section{Methods}

The private dog shelters, located in two rural areas of Sintra and Sesimbra (Central Portugal), were surrounded by abundant vegetation and trees. The shelter from Sintra, with 215 dogs under its care, was surrounded by walls about three meters high. The kennels were built with brick walls and tile ceilings. The shelter from Sesimbra, with a population of 230 dogs, was surrounded by grating two meters high and the ground was covered with cement. The kennels were built with brick walls and fiber cement ceilings, also with grating doors. The prevalence of canine leishmaniosis was 2.3\% (5/215) and 5.2\% (12/230), respectively (data not published).

Thirty rodents $(27$ Mus musculus and 3 Rattus norvegicus) were collected between May and October 2011 under a trap rodent control program applied in each private shelter. No ethical approval for animal trapping is officially required since these rodents are considered pest species. Dead specimens of Mus musculus collected from Sesimbra and Rattus norvegicus collected from Sintra were kept refrigerated for a maximum period of 6 hours before being transported to the Faculdade de Medicina Veterinária - Universidade Técnica de Lisboa (FMV/UTL) and processed by standard necropsy procedure.

The rodent's genus and species were determined by external characteristics including color, body length and ear lobes, tail, feet, teeth and cranium measurements [24].

For each rodent, liver and spleen fragments were collected and stored in 10\% formaldehyde and in RNAlater $^{\circledR}$. Imprint smears were performed from the liver and spleen. Fragments of both ear lobes were collected for RNAlater ${ }^{\circledR}$, along with tail lesions whenever observed.
Liver and spleen imprint smears were fixed with methanol for 60 seconds, stained with 10\% Giemsa for 60 seconds and observed under $1000 \times$ magnification in an optical microscope.

Formaldehyde fixed tissues were later processed routinely for paraffin embedding, $3 \mu \mathrm{m}$ sections were cut, stained with hematoxylin and eosin and observed under an optical microscope using a 400× and 1000× magnification.

Tissue samples from spleen, liver, tail and ear lobe, were sliced in 10-20 mg fragments and processed for total DNA extraction using DNeasy Blood \& Tissue Kit ${ }^{\circledR}$ (QIAGEN, Germany) following the manufacturer's instructions. Detection of Leishmania spp. nucleic acid was performed by real time PCR (qPCR) using the Applied Biosystems ${ }^{\circledR} 7300$ Real-time thermocycler. A set of primers and TaqMan ${ }^{\circledR}$ probe were calculated by the NCBI primer blast tool, available through http:// www.ncbi.nlm.nih.gov/tools/primer-blast/, based on the Leishmania sp. small circle kinetoplast nucleotide sequence, generating a forward primer 5 '-AGGTGTCGT AAATTCTGGAA-3', a reverse primer 3'-CGGGATTT CTGCACCATT and a Taqman ${ }^{\circledR}$ probe FAM $5^{\prime}$ - AATT CCAAACTTTTCTGGTCCTCCGGGTAG TAMRA - 3', spawning a 124 bp product.

The qPCR amplification was performed in a $20 \mu \mathrm{l}$ reaction volume with $2 \times$ TaqMan $^{\circledR}$ Gene Expression Master Mix (Applied Biosystems), $3 \mu \mathrm{M}$ of primer forward, $3 \mu \mathrm{M}$ of primer reverse, $2.5 \mu \mathrm{M}$ of Taqman ${ }^{\circledR}$ probe and $50 \mathrm{ng}$ of total DNA. Cycling conditions included an initial denaturation step at $95^{\circ} \mathrm{C}$ for 10 minutes followed by 50 cycles at $95^{\circ} \mathrm{C}$ for 15 seconds and $60^{\circ} \mathrm{C}$ for 1 minute.

The assay specificity was confirmed by sequencing of the amplicon after plasmid cloning (pGEM ${ }^{\circledR}$, Promega), according to the manufacturer's instructions. To estimate the parasitic load serial tenfold dilutions of the recombinant plasmid DNA were used to generate a standard curve with a $\mathrm{r} 2=0.997$ and a slope of -3.6 to -3.4 , with the 7300 System SDS software ${ }^{\circledR}$ (Applied Biosystems), corresponding to a reaction efficiency of $90 \%-100 \%$.

The assay sensitivity surpassed the detection of 10 target copies. For parasitic load quantification, only samples amplified within the $\mathrm{Ct}$ range of the standard curve were considered.

\section{Results}

\section{External examination}

In the external examination of the thirty rodents the body condition was normal, according to the species parameters. Two rodents revealed eroded tail lesions. One was detected in a Mus musculus and another in a Rattus norvegicus. The lesions measured $4 \mathrm{~mm}$ and $8 \mathrm{~mm}$ of diameter, respectively. 


\section{Parasitological analysis}

Leishmania amastigotes (Figure 1) were detected in 8 Mus musculus $(\mathrm{n}=27) ; 2$ animals were positive in both the liver smear and in the spleen histological section; 2 animals were positive in both liver and spleen smears; 3 animals were positive in the spleen histological section and 1 animal was positive in the liver smear. Concerning Rattus norvegicus $(\mathrm{n}=3)$, one animal was positive in the liver and in the spleen smears simultaneously.

All positive samples showed no more than three amastigotes per microscopic field.

\section{Molecular analysis}

Leishmania kDNA was detected in 9 ear lobe skin samples from Mus musculus. The parasitic load ranged between the detection of residual values to 393 targeted copies, indicative of low parasite burden, as already detected in the parasitological analysis (Table 1).

The tail skin lesions were negative to Leishmania kDNA, as were the liver and spleen samples from Mus musculus and Rattus norvegicus.

\section{Discussion}

Despite the possible importance of the rodent's role as reservoir hosts for canine and human leishmaniosis, to our knowledge, no previous studies on Leishmania infection in any rodent species had been published in Portugal.

Our results revealed the presence of Leishmania amastigotes in eight Mus musculus and in one Rattus norvegicus visceral sample. Despite Leishmania amastigote detection in the liver and spleen, no positive results were obtained by qPCR from these samples. Regarding nucleic acid detection, positive samples were obtained from the skin but not from the liver and spleen suggesting a cutaneous Leishmania infection. Considering the high sensitivity of the qPCR assay visceral negative results may be due to random selected fragments for amplification and microscopic observation.
In experimental studies, early dissemination of Leishmania parasites occurs in the spleen [18]. In susceptible mice, the spleen constitutes the organ where the adaptive immune response to the parasite mainly takes place. In this study, in spite of systemic dissemination being present on 6 rodent's livers (on parasitological analysis) and 8 rodent's spleens (3 on parasitological analysis and 5 on histopathological analysis), no positive results were obtained by qPCR on spleen samples. Similar PCR results were also described by other authors working with specimens of Mus musculus infected with Leishmania major [23].

In the molecular assay, 9 ear lobe skin samples from Mus musculus $(\mathrm{n}=27)$ were positive to Leishmania DNA. Although no DNA sequencing was performed, the use of a specific Taqman ${ }^{\circledR}$ probe to Leishmania infantum in the qPCR strongly suggests the detection of this species in our samples. Furthermore, Leishmania infantum is known to be the only Leishmania species causing zoonotic visceral leishmaniosis in Portugal and in the Mediterranean countries [25].

In our study, an infection rate of 33.3\% (9/27) was found in ear lobe skin of Mus musculus. This result is higher than the ones obtained in Brazil with $13.7 \%$ (3/22) [10] and Iran with $19 \%(4 / 21)$ [23]. This occurrence may have an important epidemiological role on the transmission of the parasite.

The identification of positive ear lobe skin samples in our Mus musculus rodents indicates the parasite cutaneous availability to Phlebotomus species, allowing the infection to spread during sandfly feeding, not only between rodents but also to other hosts. In fact, in an experimental study, using specimens of Rattus rattus and Leishmania tropica, the ear lobe was suggested as a preferential feeding spot for sandflies, probably due to thinner skin, easy access and abundant blood flow. In addition, the parasite DNA persisted in the ear lobe for 24 months post-inoculation and the ability to transmit the infection to sandflies from month 1 to month 24

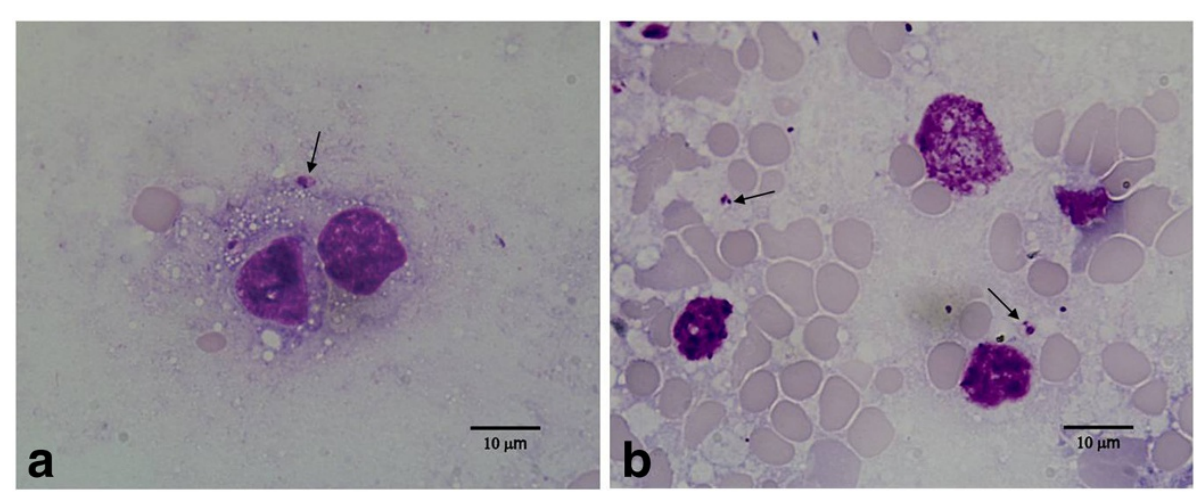

Figure 1 Leishmania amastigotes (arrows) in liver smear (a) and spleen smear (b) of Mus musculus. 
Table 1 Results obtained from molecular and parasitological analysis

\begin{tabular}{|c|c|c|c|c|c|c|c|c|}
\hline \multirow[t]{2}{*}{ Rodent species } & \multirow[t]{2}{*}{ Rodent $n^{\circ}$} & \multicolumn{3}{|c|}{ qPCR analysis (parasitic load) } & \multicolumn{4}{|c|}{ Parasitological analysis } \\
\hline & & Ear lobe & Liver & Spleen & Liver smear & Liver H.S. & Spleen smear & Spleen H.S. \\
\hline \multirow[t]{3}{*}{ Rattus norvegicus } & 1 & $\mathrm{~N}$ & $\mathrm{~N}$ & $\mathrm{~N}$ & $\mathrm{~N}$ & $\mathrm{~N}$ & $\mathrm{~N}$ & $\mathrm{~N}$ \\
\hline & 2 & $\mathrm{~N}$ & $\mathrm{~N}$ & $\mathrm{~N}$ & $\mathrm{~N}$ & $\mathrm{~N}$ & N & $\mathrm{N}$ \\
\hline & 3 & $\mathrm{~N}$ & $\mathrm{~N}$ & N & $\mathbf{P}$ & $\mathrm{N}$ & $\mathbf{P}$ & $\mathrm{N}$ \\
\hline \multirow[t]{27}{*}{ Mus musculus } & 4 & $\mathrm{~N}$ & $\mathrm{~N}$ & $\mathrm{~N}$ & $\mathbf{P}$ & $\mathrm{N}$ & $\mathbf{P}$ & $\mathrm{N}$ \\
\hline & 5 & $\mathbf{P}(72)$ & $\mathrm{N}$ & $\mathrm{N}$ & $\mathrm{N}$ & $\mathrm{N}$ & $\mathrm{N}$ & $\mathbf{P}$ \\
\hline & 6 & $\mathbf{P}(50)$ & $\mathrm{N}$ & $\mathrm{N}$ & $\mathrm{N}$ & $\mathrm{N}$ & $\mathrm{N}$ & $\mathrm{N}$ \\
\hline & 7 & $\mathrm{~N}$ & $\mathrm{~N}$ & $\mathrm{~N}$ & $\mathrm{~N}$ & $\mathrm{~N}$ & $\mathrm{~N}$ & $\mathrm{~N}$ \\
\hline & 8 & $\mathrm{~N}$ & $\mathrm{~N}$ & $\mathrm{~N}$ & $\mathbf{P}$ & $\mathrm{N}$ & $\mathrm{N}$ & $\mathrm{N}$ \\
\hline & 9 & $\mathrm{~N}$ & $\mathrm{~N}$ & $\mathrm{~N}$ & $N$ & $\mathrm{~N}$ & $\mathrm{~N}$ & $\mathrm{~N}$ \\
\hline & 10 & $\mathbf{P}(100)$ & $\mathrm{N}$ & $\mathrm{N}$ & $N$ & $\mathrm{~N}$ & $N$ & $\mathbf{P}$ \\
\hline & 11 & $\mathrm{~N}$ & $\mathrm{~N}$ & $\mathrm{~N}$ & $\mathrm{~N}$ & $\mathrm{~N}$ & $\mathrm{~N}$ & $\mathrm{~N}$ \\
\hline & 12 & $\mathrm{~N}$ & $\mathrm{~N}$ & $\mathrm{~N}$ & $\mathrm{~N}$ & $\mathrm{~N}$ & $\mathrm{~N}$ & $\mathrm{~N}$ \\
\hline & 13 & $\mathbf{P}(393)$ & $\mathrm{N}$ & $\mathrm{N}$ & $\mathrm{N}$ & $\mathrm{N}$ & $\mathrm{N}$ & $\mathrm{N}$ \\
\hline & 14 & $\mathrm{~N}$ & $\mathrm{~N}$ & $\mathrm{~N}$ & N & $\mathrm{N}$ & $\mathrm{N}$ & $\mathrm{N}$ \\
\hline & 15 & $\mathrm{~N}$ & $\mathrm{~N}$ & $\mathrm{~N}$ & $\mathrm{~N}$ & $\mathrm{~N}$ & $\mathrm{~N}$ & $\mathrm{~N}$ \\
\hline & 16 & $\mathrm{~N}$ & $\mathrm{~N}$ & $N$ & $\mathrm{~N}$ & $\mathrm{~N}$ & $N$ & $\mathrm{~N}$ \\
\hline & 17 & $\mathrm{~N}$ & $\mathrm{~N}$ & $\mathrm{~N}$ & $\mathbf{P}$ & $\mathrm{N}$ & $N$ & $P$ \\
\hline & 18 & $\mathrm{~N}$ & $\mathrm{~N}$ & $\mathrm{~N}$ & $\mathrm{~N}$ & $\mathrm{~N}$ & $\mathrm{~N}$ & $\mathrm{~N}$ \\
\hline & 19 & $\mathbf{P}(50)$ & $\mathrm{N}$ & $\mathrm{N}$ & $P$ & $\mathrm{~N}$ & $\mathbf{P}$ & $\mathrm{N}$ \\
\hline & 20 & $\mathrm{~N}$ & $\mathrm{~N}$ & $\mathrm{~N}$ & $\mathrm{~N}$ & $\mathrm{~N}$ & $\mathrm{~N}$ & $\mathrm{~N}$ \\
\hline & 21 & $\mathrm{~N}$ & $\mathrm{~N}$ & $\mathrm{~N}$ & $N$ & $\mathrm{~N}$ & $\mathrm{~N}$ & $\mathrm{~N}$ \\
\hline & 22 & $\mathrm{~N}$ & $\mathrm{~N}$ & $\mathrm{~N}$ & $N$ & $\mathrm{~N}$ & $N$ & $\mathrm{~N}$ \\
\hline & 23 & $\mathrm{~N}$ & $\mathrm{~N}$ & $\mathrm{~N}$ & $\mathrm{~N}$ & $\mathrm{~N}$ & $\mathrm{~N}$ & $\mathrm{~N}$ \\
\hline & 24 & $\mathbf{P}$ (resid) & $\mathrm{N}$ & $\mathrm{N}$ & $\mathrm{N}$ & $\mathrm{N}$ & $N$ & $\mathrm{~N}$ \\
\hline & 25 & $\mathrm{~N}$ & $\mathrm{~N}$ & $\mathrm{~N}$ & $\mathrm{~N}$ & $\mathrm{~N}$ & $N$ & $\mathrm{~N}$ \\
\hline & 26 & $\mathrm{~N}$ & $\mathrm{~N}$ & $\mathrm{~N}$ & $N$ & $\mathrm{~N}$ & $\mathrm{~N}$ & $\mathrm{~N}$ \\
\hline & 27 & $\mathbf{P}$ (resid) & $\mathrm{N}$ & $\mathrm{N}$ & $\mathrm{N}$ & $\mathrm{N}$ & $\mathrm{N}$ & $\mathbf{P}$ \\
\hline & 28 & $\mathrm{~N}$ & $N$ & $\mathrm{~N}$ & $N$ & $\mathrm{~N}$ & $N$ & $\mathrm{~N}$ \\
\hline & 29 & $\mathbf{P}$ (resid) & $\mathrm{N}$ & $N$ & $N$ & $\mathrm{~N}$ & $N$ & $\mathrm{~N}$ \\
\hline & 30 & $\mathbf{P}$ (resid) & $\mathrm{N}$ & $N$ & $P$ & $\mathrm{~N}$ & $N$ & $\mathbf{P}$ \\
\hline
\end{tabular}

Legend: P: Positive result; N: Negative result; H.S.: Histological section; resid: residual.

post-inoculation was observed [26]. Although the parasite number in the blood was not assessed in this work, considering that the parasite load ranged between 50 to 393 copies in 5 animals, it is safe to conclude that the parasites were present in the skin in sufficient numbers to infect sandflies. Unfortunately, in this work, it was not possible to perform specific antibody titers to correlate data with the obtained molecular results.

This work reports for the first time in Portugal, the natural infection of Leishmania infantum in Mus musculus and Rattus norvegicus, suggesting these animals probably have a role as reservoirs in the Leishmania infantum life cycle. Mus musculus and Rattus norvegicus are extremely prolific animals, with a 12 and 24 months life expectancy respectively, maintaining the parasite availability at least for one year, even during low sandfly activity season. The infection rate obtained by $\mathrm{qPCR}$ on Mus musculus rodents (33.3\%) strongly suggests the occurrence of contact with infected sandflies, especially considering the preferential nightfall activity period overlap. Also, the absence of skin lesions strongly suggests a non-pathogenic infection course, as already described in Brazil [10,11] and in Iran $[22,23]$.

This study was performed in a peridomestic environment in two regions, with a canine leishmaniosis prevalence of 2.3\% (5/215) in Sintra and 5.2\% (12/230) in Sesimbra. Mus musculus and Rattus norvegicus were found to be naturally infected by Leishmania infantum 
with an overall prevalence of $43.3 \%$ (13/30). These species are known to inhabit in close proximity to human housing, especially where shelter and food are provided like those found in Sesimbra and Sintra. This process of domiciliation may be important in the urban and periurban cycle of Leishmania infantum. Further studies are necessary to evaluate the ability of these rodents to effectively infect vector sandflies in order to establish Mus musculus and Rattus norvegicus as reservoir hosts for Leishmania infantum.

As susceptible hosts with a potential role in the epidemiology of this zoonotic disease, infected rodents may increase the risk for dog and human infection in households and surrounding areas, enhancing the need for an efficient rodent control measure in shelters and risk zones to prevent the transmission.

\section{Conclusions}

This work reports for the first time in Portugal, the natural infection of Leishmania infantum in Mus musculus and Rattus norvegicus, implicating these animals as possible reservoirs in the Leishmania infantum life cycle, according to the established criteria by WHO [6]. As susceptible hosts with a potential role in the epidemiology of this zoonotic disease, infected rodents may increase the risk for dog and human infection in households and surrounding areas, enhancing the need for efficient rodent control measures in shelters and risk zones to prevent the transmission of infection.

\section{Competing interests}

Authors declare that they have no competing interests whatsoever.

\section{Authors' contributions}

$\mathrm{MH}$ - Study design support, parasitological studies carried out, research and draft of the manuscript JPL - Study conception, design and coordination, parasitological work support, research and manuscript draft support. AD - Molecular studies carried out, data interpretation and manuscript draft support. LT - Molecular studies work out, data interpretation and manuscript draft support IPF - Study design and coordination, data interpretation, and manuscript draft support. All authors read and approved the final version of the manuscript.

\section{Acknowledgements}

This work was sponsored by the project PTDC/CVT/118566/2010 and by FCT/ CIISA. We also acknowledge the dog shelter directors and staff, the Parasitology, Virology and Histology department's staff of FMV/UTL and Dr. Cátia Marques for image support.

\section{Author details}

${ }^{1}$ CIISA, Fac Med Vet, Av, Universidade Técnica, 1300-477, Lisboa, Portugal. ${ }^{2}$ Centro Médico Veterinário de Cabra Figa, Rua da Liberdade, lote 889-A Cabra Figa, 2635-128, Rio de Mouro, Portugal.

Received: 18 January 2013 Accepted: 28 March 2013 Published: 8 April 2013

\section{References}

1. Ashford RW: Leishmaniasis reservoirs and their significance in control. Clin Dermatol 1996, 14:523-532.

2. Ashford RW: The leishmaniasis as emerging and reemerging zoonosis. Int J Parasitol 2000, 30:1269-1281.
3. Colwell DD, Dantas-Torres F, Otranto D: Vector-borne parasitic zoonoses: Emerging scenarios and new perspectives. Vet Parasitol 2011, 182:14-21.

4. Cortes S, Vaz Y, Neves R, Maia C, Cardoso L: Campino: Risk factors for canine leishmaniasis in an endemic Mediterranean region. Vet Parasitol 2012, 189:189-96.

5. Cardoso L, Lopes AP, Sherry K, Schallig H, Solano-Gallego L: Low seroprevalence of Leishmania infantum infection in cats from northern Portugal based on DAT and ELISA. Vet Parasitol 2010, 174:37-42.

6. WHO: The vector-borne human infections of Europe. Their distribution and burden on Public Health. 2004:27-30. Available at: http://www.euro.who. int/_data/assets/pdf_file/0008/98765/e82481.pdf.

7. Campino L, Maia C: Epidemiologia das leishmanioses em Portugal. Acta Med Port 2010, 23:859-864.

8. Center for Food Security and Public Health, Institute for International Cooperation in Animal Biologics \& OlE: Leishmaniasis (cutaneous and visceral). 2009:2-3. Available at: http://www.bibliotecadigital.ufmg.br/dspace/ handle/1843/360/browse?value=Hessem+Miranda+Neiva\&type=author.

9. Neiva H: Frequência de anticorpos de Leishmania sp. em Rattus norvegicus no município de Belo Horizonte, Minas Gerais. 2005. Brasil: Dissertação de Mestrado em epidemiologia. Escola de Veterinária - Universidade Federal de Minas Gerais; 2005:18-23. Available at: http://dspace.lcc.ufmg.br/dspace/bitstream/1843/BUOS8BYHAH/1/disserta_o_de_mestrado_de_hessem_miranda_neiva.pdf.

10. Melo L: Detecção de Leishmania sp. em pequenos mamíferos silvestres e sinantrópicos no município de Belo Horizonte, MG. Dissertação de Pósgraduação em Ciências da Saúde. Centro de pesquisas René Rachou, Fundação Oswaldo Cruz; 2008:44-72. available at: http://netra.cpqrr.fiocruz. br/download/Dissertacao_Lutiana_Amaral_de_Melo.pdf.

11. Júnior J: Infecção natural por Leishmania spp. em pequenos mamíferos silvestres e sinantrópicos envolvidos na manutenção da leishmaniose tegumentar americana em área endémica da Zona da Mata Norte de Pernambuco, Brasil. Dissertação de Mestrado em Saúde Pública. Fundação Oswaldo Cruz; 2010:36-56. Available at: http://www.cpqam.fiocruz.br/ bibpdf/2010marinhojunior-jf.pdf.

12. Oliveira F, Pirmez C, Pires M, Brazil R, Pacheco R: PCR-based diagnosis for detection of Leishmania in skin and blood of rodents from an endemic area of cutaneous and visceral leishmaniasis in Brazil. Vet Parasitol 2005, 129:219-227.

13. Zulueta A, Villarroel E, Rodriguez N, Feliciangeli M, Mazarri M, Reyes $\mathrm{O}$, Rodriguez V, Centeno M, Barrios R, Ulrich M: Epidemiological aspects of american visceral leishmaniasis in an endemic focus in eastern Venezuela. Am Trop Med Hyg 1999, 61:945-950.

14. De Lima H, De Guglielmo Z, Rodríguez A, Convit J, Rodriguez N: Cotton rats (Sigmodon hispidus) and black rats (Rattus rattus) as possible reservoirs of Leishmania spp. in Lara state, Venezuela. Mem Inst Oswaldo Cruz, Rio de Janeiro 2002, 97:169-174.

15. Canto-Lara S, Wynsberghe N, Vargas-González A, Ojeda-Farfán F, AndradeNarváez F: Use of monoclonal antibodies for the identification of Leishmania spp. isolated from humans and wild rodents in the State of Campeche, México. Mem Inst Oswaldo Cruz, Rio de Janeiro 1999, 94:305-309.

16. Di Bella C, Vitale F, Russo G, Greco A, Milazzo C, Aloise G, Cagnin M: Are rodents a potencial reservoir for Leishmania infantum in Italy? J M Eco 2003, 7(Suppl):125-129.

17. Psaroulaki A, Antoniou M, Toumazos P, Mazeris A, Loannou I, Chochlakis D, Christophi N, Loukaides P, Patsias A, Moschandrea I, Tselentis Y: Rats as indicators of the presence and dispersal of six zoonotic microbial agents in Cyprus, an island ecosystem: a seroepidemiological study. Trans $R$ SoC Trop Med Hyg 2010, 104:733-739.

18. Papadogiannakis E, Spanakos G, Kontos V, Menounos PG, Tegos N, Vakalis N: Molecular detection of Leishmania infantum in wild rodents (Rattus norvegicus) in Greece. Zoonoses Public Health 2010, 57:e23-e25.

19. Mohebali M, Javadian E, Yaghoobi-Ershadi M, Akhavan AA, Hajjaran H, Abaei MR: Characterization of Leishmania infection in rodents from endemic areas of the Islamic Republic of Iran. East Mediterr Health J 2004, 10:591-9.

20. Pourhohammadi B, Motazedian MH, Kalantari M: Rodent infection with Leishmania in a new focus of human cutaneous leishmaniasis, in northern Iran. Ann Trop Med Parasitol 2008, 102:127-133.

21. Akhavan A, Mirhendi H, Khamesipour A, Alimohammadian M, Rassi Y, Bates P, Kamhawi S, Valenzuela J, Arandian M, Abdoli H, Jalali-zand N, Jafari R, Shareghi N, Ghanei M, Yaghoobi-Ershadi M: Leishmania species: Detection and identification by nested PCR assay from skin samples of rodent reservoirs. Exp Parasitol 2010, 126:552-556. 
22. Motazedian M, Parhizkari M, Mehrabani D, Hatam G, Asgari Q: First detection of Leishmania major in Rattus norvegicus from Fars Province, Southern Iran. Vector Borne Zoonotic Dis 2010, 10:969-75.

23. Parhizkari M, Motazedian MH, Asgari Q, Mehrabani D: The PCR-based detection of Leishmania major in Mus musculus and other rodents caught in Southern Iran: A guide to sample selection. Ann Trop Med Parasitol 2011, 105:319-323.

24. Ministério da Saúde: Manual de Controle de Roedores - vigilância Epidemiológica. Brasilia: Funasa; 2002:20-21. Available at: http://portal.saude. gov.br/portal/arquivos/pdf/manual_roedores.pdf.

25. Ready PD: Leishmaniasis emergence in Europe. Euro Surveill 2010, 15:3-4. Available at: http://eurosurveillance.org/images/dynamic/EE/N15N10/ art19505.pdf.

26. Svobodová M, Votýpka J, Nicolas L, Volf P: Leishmania tropica in the black rat (Rattus rattus): persistence and transmission from asymptomatic host to sand fly vector Phlebotomus sergenti. Microbes Infect 2003, 5:361-364.

doi:10.1186/1756-3305-6-88

Cite this article as: Helhazar et al:: Natural infection of synathropic rodent species Mus musculus and Rattus norvegicus by Leishmania infantum in Sesimbra and Sintra - Portugal. Parasites \& Vectors 2013 6:88.

\section{Submit your next manuscript to BioMed Central and take full advantage of:}

- Convenient online submission

- Thorough peer review

- No space constraints or color figure charges

- Immediate publication on acceptance

- Inclusion in PubMed, CAS, Scopus and Google Scholar

- Research which is freely available for redistribution 